\title{
The praxis and politics of building urban dashboards
}

\author{
Rob Kitchin ${ }^{\mathrm{a}, *}$, Sophia Maalsen ${ }^{\mathrm{b}}$, Gavin McArdle ${ }^{\mathrm{c}}$ \\ ${ }^{a}$ National Institute for Regional and Spatial Analysis, National University of Ireland Maynooth, Ireland \\ ${ }^{\mathrm{b}}$ School of Geosciences, University of Sydney, Australia \\ ${ }^{\mathrm{c}}$ School of Computer Science, University College Dublin, Ireland
}

\section{A R T I C L E I N F O}

\section{Article history:}

Received 21 May 2015

Received in revised form 12 September

2016

Accepted 7 October 2016

Available online 18 October 2016

\section{Keywords:}

Dashboard

Data

Dublin

Politics

Smart city

\begin{abstract}
A B S T R A C T
This paper critically reflects on the building of the Dublin Dashboard - a website built by two of the authors that provides citizens, planners, policy makers and companies with an extensive set of data and interactive visualizations about Dublin City, including real-time information - from the perspective of critical data studies. The analysis draws upon participant observation, ethnography, and an archive of correspondence to unpack the building of the dashboard and the emergent politics of data and design. Our findings reveal four main observations. First, a dashboard is a complex socio-technical assemblage of actors and actants that work materially and discursively within a set of social and economic constraints, existing technologies and systems, and power geometries to assemble, produce and maintain the website. Second, the production and maintenance of a dashboard unfolds contextually, contingently and relationally through transduction. Third, the praxis and politics of creating a dashboard has wider recursive effects: just as building the dashboard was shaped by the wider institutional landscape, producing the system inflected that landscape. Fourth, the data, configuration, tools, and modes of presentation of a dashboard produce a particularised set of spatial knowledges about the city. We conclude that rather than frame dashboard development in purely technical terms, it is important to openly recognize their contested and negotiated politics and praxis.
\end{abstract}

(c) 2016 Elsevier Ltd. All rights reserved.

\section{Introduction}

There is a long history of cities generating data about their form and activities and distilling such data into information and knowledge to manage and control urban operations and guide and evaluate public policy. Over the past fifty years, much of these data have been digital in nature and the increasing power of computation has been used to process, analyze and store them, for example, through information management systems, spreadsheets, stats packages, and geographic information systems. More recently, there has been a step change in the production of urban data through the embedding of computation into the fabric and infrastructure of cities - what Greenfield (2006) describes as the creation of 'everyware' - to produce a new form of data-rich and datadriven urbanism (Shepard, 2011; Kitchin and Dodge, 2011). Here, a variety of devices, cameras, transponders, actuators and sensors, each producing streams of big data that can be processed and responded to in real-time, are used to augment and mediate the

\footnotetext{
* Corresponding author.

E-mail addresses: rob.kitchin@nuim.ie (R. Kitchin),sophia.maalsen@sydney.edu. au (S. Maalsen), gavin.mcardle@ucd.ie (G. McArdle).
}

operation and governance of urban systems (Kitchin, 2014a). These machine-readable and controllable environments form a critical part of the present drive to create a new form of urbanism, what is widely termed 'smart cities' (Townsend, 2013).

The introduction of 'smart cities' into the urban and popular lexicon is a relatively recent phenomenon, popularised through an aggressive IBM marketing campaign started in 2010, accompanied by the efforts of several other large multinationals looking to generate a new city market for their technologies and services, and the place marketing of a number of cities seeking to re-brand and re-position themselves in the global city hierarchy. It is, however, the latest stage in the evolution of networked urbanism that has been developing rapidly since the late 1980s (Graham and Marvin, 2001) that has variously been termed 'wired cities' (Dutton et al., 1987), 'cyber cities' (Graham and Marvin, 1999), 'digital cities' (Ishida and Isbister, 2000), 'intelligent cities' (Komninos, 2002), and 'sentient cities' (Shepard, 2011). Whilst the definition of smart cities is somewhat open and contested within the literature and among stakeholders, smart city advocates generally agree that a smart city is one that strategically uses information and communication technologies (ICT) and associated big data and data analytics to improve existing city services and create 
new services, engage citizens, foster sustainability and resilience, solve urban issues, and stimulate innovation and grow the local economy.

In such a vision, the generation and analysis of contextual and actionable data is a central pillar, with the city becoming increasingly knowable and controllable in new dynamic ways. As such, accompanying the rise of networked urbanism has been an increased emphasis on harvesting, collating, processing and analyzing urban data across all aspects of city life and urban systems. Correspondingly, since the early 1990s there has been the growth of two related phenomena. First, a proliferation of urban indicator and city benchmarking projects utilising administrative and official statistical data. These were given impetus by the sustainability agenda arising from the 1992 United Nations Conference on Environment and Development (UNCED) and the publication of Chapter 40 of Agenda 21 which called for sustainable development indicators to be developed to provide an evidence base for decision-making, and by the rise of new managerialism and the desire to reform the public sector management of city services to make them more efficient, effective, transparent and value for money (Innes and Booher, 2000; Holden, 2006). The result has been the development of city indicator systems such as Citistat and accompanying forms of performance indicator-driven urban management (Behn, 2014; Kitchin et al., 2015), and the adoption of an ISO (International Organisation for Standardization) standard for city indicators (ISO 37120:2014). Second, the expansion of a diverse set of urban control rooms of varying kinds (e.g., security, transport, utilities) capable of handling so-called big data (generated in real time, exhaustive to a system, and large in volume). Such control rooms, utilising SCADA systems can be traced back to the mid-twentieth century, but have multiplied with the growth of networked urbanism (Luque-Ayala and Marvin, 2016).

Increasingly, urban administrative and operational data are being centralised into single city operating systems and facilities, collapsing the walls between data silos and enabling a more holistic and integrated view of city services and infrastructures that can guide daily operations and long term planning and policy formulation. The archetypal example of such a system is the Centro De Operacoes Prefeitura Do Rio in Rio de Janeiro, Brazil, a datadriven city operations centre that pulls together into a single location real-time data streams from thirty agencies, including traffic and public transport, municipal and utility services, emergency and security services, weather feeds, information generated by employees and the public via social media, as well as administrative and statistical data. These data are overseen and processed by a staff of 400 operatives working across three shifts to provide twenty-four hour analyses and services.

A key approach to making sense of such data has been a new suite of visual analytics that are dynamic, interactive, interlinked, and use traditional graphs, charts and maps, as well as more innovative visual presentations such as gauges, 3D models and augmented landscape images made possible by advanced computer graphics (Keim et al., 2010). Unsurprisingly then, a key feature of urban control rooms are banks of computer screens displaying visualised data. Such data are often presented and navigated through a dashboard interface. Dashboards provide a visual means to organize and interact with data, enabling users to drill down into data sets, filter out uninteresting data, select an item or group of data and retrieve details, view relationships among items, extract sub-collections, and to overlay and interconnect disparate data, enabling summary-to-detail exploration within a single visualisation system (Dubriwny and Rivards, 2004; Few, 2006). Dashboards act as cognitive tools that improve the user's 'span of control' over a large repository of voluminous, varied and quickly transitioning data (Brath and Peters, 2004) and enable a user to explore the characteristics and structure of datasets and interpret trends without the need for specialist analytics skills (the systems are point and click and require no knowledge of how to produce such graphics). They can also facilitate the exporting of visualizations for use in documents, or sharing via social media, or accessing the underlying data for importing into other analytical packages. With the recent drive towards producing open data, some of the data feeding urban control rooms and city dashboards, as well as wider administrative and statistical data, are becoming freely available for wider deployment. As such, other parties are able to use the data to conduct their own analyses, build city apps, and create their own urban dashboards. And in some cases, the city itself is publicly sharing data and visualizations via an open dashboard.

The power and utility of urban dashboards is their claim to show in detail and often in real-time the state of play of cities. As Kitchin et al. (2015: 12-13) put it, urban dashboards purport to "enable us to know the city as it actually is through objective, trustworthy, factual data that can be statistically analyzed and visualised to reveal patterns and trends and to assess how it is performing vis-a-vis other places. [They supply] a rational, neutral, comprehensive and commonsensical evidential basis for monitoring and evaluating the effectiveness of urban services and policy, to develop new interventions, and to learn and manage through measurement." In so doing, dashboards facilitate the illusion that it is possible to "picture the totality of the urban domain", to translate the messiness and complexities of cities into rational, detailed, systematic, ordered forms of knowledge (Mattern, 2014). In other words, they provide a powerful realist epistemology for monitoring and understanding cities, underpinned by an instrumental rationality in which 'hard facts' trump other kinds of knowledge and provide the basis for formulating solutions to urban issues (Kitchin et al., 2015; Mattern, 2014, 2015). As such, they seemingly provide a neutral and value-free medium through which to govern and plan a city. Indeed, dashboard initiatives have become central to the regimes of urban governance in many cities, either providing a means to assess, guide and resource daily operational practices across public services and/or provide wider contextual information that shapes policy formulation and planning (Edwards and Thomas, 2005; Gullino, 2009; Behn, 2014).

In contrast to such thinking and framing, the realist epistemology and instrumental rationality of urban dashboards has been critiqued from a number of perspectives. First, dashboards, it is contended, are not simply neutral, technical, commonsensical tools, but rather are framed socially, political, ethically, philosophically in terms of their form, selection of data, modes of display and analysis, and deployment (Kitchin et al., 2015). Urban dashboards are the product of the ideas, instruments, practices, contexts, knowledges and systems used to generate, process and analyze them. This is often keenly understood by the designers of such systems, who are aware of the technical limitations and design and policy implications of indicators (Sawicki and Flynn, 1996; Wong, 2006; Behn, 2014), though they seemingly practice a form of strategic essentialism in their promotion and deployment (Kitchin et al., 2015), but can be somewhat less appreciated by city administrators.

Second, dashboards act as translators and engines rather than mirrors, deploying a communicative protocol that frames how data are visualised and thus what the user can see and engage with, and what questions can be asked and how the answers are displayed (Franceschini et al., 2007; Galloway, 2012; Mattern, 2014, 2015). Dashboards do not simply represent urban phenomena, but generate new visions and understandings of the city; they actively produce meaning and do work in the world. Moreover, they deploy a global scopic system of generalized visual forms that occludes certain forms of knowledge and keep black-boxed the algorithms, databases, software and design decisions that shape the interface's 
look-and-feel and operation (Drucker, 2013). In order words, the dashboard interface is not a neutral, value-free medium, but rather profoundly influences its message and use.

Third, dashboards are reductive, atomizing complex, contingent relationships into relatively simple visualised measures that obscures the multidimensional nature of cities. Moreover, they decontextualize a city from its history, its political economy, the wider set of social, economic and environmental relations, and its wider interconnections and interdependencies that stretches out over space and time (Craglia et al., 2004; Mori and Christodoulou, 2012). In so doing, dashboards suggest that a city is simply the sum of its measures and be can be known, planned and controlled through data processes and algorithms alone; that a city is simply a system that acts in a 'rational, mechanical, linear and hierarchical' way and 'can be steered and controlled' much like a car is through its dashboard (Block et al., 2013: 105). Instead, cities are complex, open and contested systems, full of culture, politics, inequalities, and messy social realities that cannot simply be pushed, pulled and directed through data-informed levers.

Taken together, these critiques contend that far from being neutral, objective, apolitical communication tools, dashboards are inherently active and ideological. They express a particular vision of cities and urban governance; a normative notion about what should be measured, what should be asked, and what should be revealed; and they have normative effect, shaping decisionmaking and behaviour (Kitchin et al., 2015). Each dashboard is a complex socio-technical system, composed of many apparatuses and elements that are thoroughly entwined and shape each other through a contingent and complex web of multifaceted relations and condition how a dashboard is formulated, developed, administered, deployed, and used.

Drawing on the call to chart and unpack data assemblages within the nascent field of critical data studies (Dalton and Thatcher, 2014; Kitchin and Lauriault, 2014), in this paper we trace the constituent apparatus and elements of the Dublin Dashboard, an extensive, open, analytical dashboard launched in September 2014, and the praxis and politics involved in its unfolding development from initial conception through to its launch. The Dublin Dashboard (http://www.dublindashboard.ie) provides citizens, planners, policy makers and companies with an extensive set of data and interactive data visualizations about Dublin City, including real-time information, indicator trends, inter and intra-urban benchmarking, interactive maps, location-based services, a means to directly report issues to city authorities, and links to city apps. The data used in the Dashboard is open and available for others to build their own apps.

The analysis draws on a combination of ethnography and participant observation - two of the authors (Kitchin and McArdle) were lead developers responsible for the design and undertaking the building of the dashboard and the third (Maalsen) was employed as an ethnographer on the project for six months, attending internal development meetings and external meetings with the local authority stakeholder and two companies. Whilst one or both of the two developers attended all internal meetings (c. 20 mostly informal meetings arranged on an ad hoc basis) and external meetings ( 14 formally arranged meetings with stakeholders and interested parties), the ethnographer attended seven external meetings and six internal meetings and conducted an interview with one of the lead developers. In all cases, the ethnographer acted as an observer at meetings, taking notes with regards to the conversations and decisions taken, with just one internal meeting and the interview being voice recorded. In addition, the whole of the launch event was video recorded and all email exchanges between participants were available for analysis.

\section{Building the Dublin Dashboard}

Unlike most urban dashboards, the Dublin Dashboard was initiated as a university research project rather than by a city administration. The aim was to explore the praxes and politics of developing urban dashboards as part of the Programmable City project (for which Rob Kitchin is principal investigator; http:// progcity.maynoothuniversity.ie/) through the process of building one, leveraging and extending existing geospatial visualisation work that had been in progress since 2005 through the All-Island Research Observatory (AIRO) initiative (http://www.airo.ie). AIRO has undertaken spatial data visualisation work for the majority of local and regional authorities and government departments in Ireland, as well for a number of state agencies and public sector bodies in Northern Ireland. Given that most of the data required was in the public domain, our experience of producing data visualisation tools about places independent of their governance, and for the sake of expediency in applying for funds, none of the four Dublin local authorities were approached whilst formulating the project proposal.

After funding was granted the first internal team meeting took place in early November 2013 between the principal investigator and the newly appointed developer. In effect this meeting constituted an initial requirements analysis which constitutes a standard part of software development, though in this case it did not involve consulting a client. The meeting explored more fully: the proposed parameters, scope and principles of the envisaged dashboard, identifying desirable datasets and their necessary characteristics, discussing the organisation of the site, the potential look and feel of the interface, and the possible software to be used; sketched out a basic strategy and timeline of development; and set out what research needed to be undertaken in the short term. This process unfolded in a contingent and relational manner, shaped by prior practical knowledge and experience, technical expertise, knowledge of the literature and other urban dashboards, and researcher expectations. The two participants explored and debated different options, (mostly) settled differences of opinion, negotiated common positions, and developed an initial sense of the project and principles. In particular, we were influenced by the CASA (Centre for Advanced Spatial Analysis) London city dashboard (real-time data; http://citydashboard.org/london/) and the London Dashboard (public administration and statistical data; http://data.london.gov. uk/london-dashboard), with which we were both familiar, and the idea of combining elements of both into one system. Indeed, we spent quite some time jointly examining and discussing these two sites, as well as others.

It was decided that the dashboard would consist of a set of indicator modules that would enable the following questions to be answered: how well is Dublin performing? how does Dublin compare to other places? and what's happening in the city right now? In order to achieve answers for the first two questions it was agreed that we would need data generated annually or subannually at the scale of Dublin or preferably more fine-grained. It is only with such temporal and spatial resolution that trends can be tracked in a timely fashion and with location specificity. With regards to the latter question we would need to source real-time data, some of which we knew were available through Dublinked, the city's open data store (http://www.dublinked.ie). Where possible we decided we would try to use open source tools. It was decided that our initial basic underlying principles for the site were that: there would be no closed elements with all of the visualizations on the site are accessible to everyone; all of the data used on the site would be open in nature, enabling others to access them and build their own apps; the site would be easy to use, with users 
requiring no mapping or graphing skills; and the site would be interactive allowing users to explore the data.

At the end of the meeting it was decided that the initial research would consist of three main tasks. First, conduct a detailed data audit of the city, identifying what datasets existed, their spatial and temporal characteristics, who held them, if they were public domain, and the data format and standards. Our hunt for suitable indicator datasets was guided by previous audit work conducted by AIRO, the London Dashboard, and the 100 key indicators detailed in the then forthcoming ISO 37120 standard for city indicators (http://www.cityindicators.org). We chose the London datastore as it had a good range of different kinds of indicators. Likewise, the ISO standard as it included a diverse selection of indicators designed to measure how a city was performing and had the potential to become a global benchmarking baseline for cities having been endorsed by a number of global agencies and adopted by over 280 cities. Second, explore other city dashboards, and dashboards and open data sites more generally to expand our knowledge of the content, look-and-feel and ethos of those initiatives, and to see what approaches and tools we could potentially borrow. Third, produce an initial mock-up of what a Dublin Dashboard might look like. Our intention was to build a working prototype and then to approach Dublin City Council (DCC) with a view to forming a working relationship to seek additional datasets and institutional stakeholder support. We held a subsequent meeting shortly after the first to sketch out possibilities, including a discussion of a classification scheme for dividing up indicators into broad classes. This scheme progressed through several iterations (and continued to be refined in subsequent meetings largely in line with the availability of suitable data to populate categories).

Along with our initial decisions, these three tasks set an initial pathway for subsequent work, opening up certain possibilities whilst closing down others. If a different set of principles had been decided on, or different decisions had been made, or different dashboards had been used as inspiration, then the dashboard developed would have alternative tools, content, and look and feel. Indeed, this contingency and path dependency was illustrated almost immediately through a disruptive encounter. In midDecember, the Office of International Relations and Research Office (OIRRO) in Dublin City Council (DCC) informed AIRO that it was in the process of formulating a tender for the development of a 'Data Visualisation of a Dublin Indicator Database' that appeared to overlap significantly with some of the work we were undertaking on the prototype dashboard. Five days later we had our first meeting with a member of OIRRO in DCC where we set out what we were doing and he detailed what DCC were envisaging, and there was a general exchange of knowledge and ideas. The result of the meeting was an agreement that we would continue to develop the dashboard and DCC would supply a spreadsheet of data they were hoping to include in their data visualisation suite for inclusion in the dashboard. We would also explore the possibility of sourcing data for the 37 indicators across 10 themes identified as desirable indicators by DCC in their recent sustainability report (Dublin City Council, 2012). We would then meet again in the new year for further discussion.

Through this encounter the data audit work and potential content for the dashboard was re-directed, albeit not in a substantial way. The underlying principles were not challenged, nor were the initial design ideas. More importantly, however, the constitution of the nascent socio-technical assemblage was altered with the addition of a new core institution, with different knowledges, priorities and expectations, shaping the requirements and decision-making. In February DCC became a sponsoring partner in the project, although it would only contribute resources inkind through occasional staff time with regards to consultation meetings and securing additional data. To date, no contract has been signed with DCC or any other potential stakeholder and the site is hosted on a university server, nor has there been a formal discussion as to the maintenance and on-going development and delivery of the Dublin Dashboard in the long-term. Thus the legal basis of the assemblage has not formalised as would be the case for other urban dashboards, especially those sourced through procurement.

During January 2014 the data audit was completed. This research had consisted of an extensive trawl of local authority, government department and state agency websites, and liaison with stakeholder contacts and members of the open data community to compile a database of Dublin-related data. Where the data was publicly available it was downloaded and examined as to its suitability for inclusion based on its spatial and temporal granularity and quality. This often involved extensive discussion and debate about data veracity and lineage and possible proxies when the required data was missing or not published with sufficient granularity. We also examined the data supplied to us by DCC and sought to source the data for the desired 37 indicators. It soon became apparent that sourcing suitable data for some indicator themes, such as education, health and demography was impossible beyond the five yearly census data. Of the 37 indicators desired by DCC only 10 were available at a Dublin city or finer scale on an annual/sub-annual basis (one of which has subsequently become unavailable due to privatisation (water consumption)), meaning that certain requirements could not be fulfilled.

Two subsequent meetings took place with OIRRO at DCC to discuss and review the proposed data sources and to demonstrate the site as was and solicit feedback. Based on these meetings and internal team discussion, a couple of weeks later the lead developers decided to change quite markedly the scope of the dashboard. This decision was taken to widen the scope, appeal and utility of the site beyond the selected indicator, benchmarking and real-time data by including as much data about the city as possible and providing more analytic tools, in large part by drawing on and leveraging already existing resources in AIRO and elsewhere. In this expanded vision, the dashboard would become a mix of data visualisation site and portal, and would include a set of interactive mapping modules displaying census, housing, crime, welfare, planning and land use data, as well as the location and accessibility of services, and links to city benchmarking sites, city apps, data stores, and crowdsourced reporting of city issues.

In other words, there was a fairly radical rupture in the contingent unfolding of development of the dashboard. In essence, two new principles were added-as much data as possible, regardless of source or type, would be made available through the site; and existing resources and apps would be used if they did a good job to remove duplication of effort-and the requirements were reframed to allow additional questions to be asked: where are the nearest facilities/services to me? what are the spatial patterns of different phenomena? what are the future development plans for the city? how do I report issues about the city? how can I freely access data about the city? Over time, it was envisaged that interactive maps of social media activity and a modelling module that would enable simulation and predictive profiling of city development might be added. Over the next three weeks a new dashboard design was implemented to reflect the new vision, changing markedly the look and feel, and it was iterated again a couple of months later as new modules were created/added. Fig. 1 displays four of those iterations as the design changed in line with the evolving remit and content of the dashboard.

The newly conceived site was presented to OIRRO at a meeting at DCC in March, with few requests for changes or suggestions for project development. In contrast to other projects we have conducted with stakeholders, there was little attempt by DCC to overtly steer or control the direction of the dashboard, and con- 
Dec 2013 - Feb 2014

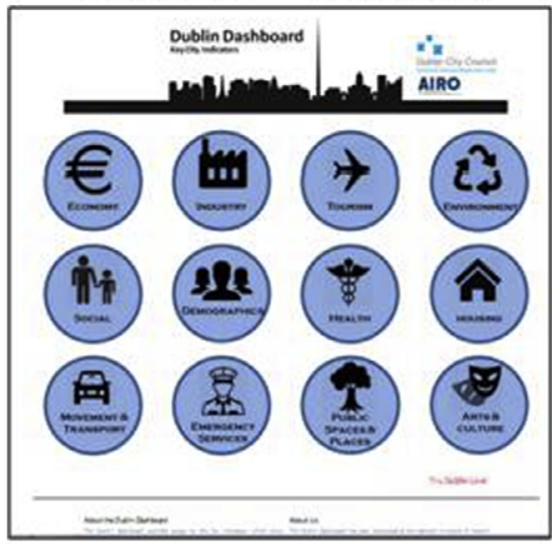

June 2014 - Feb 2015

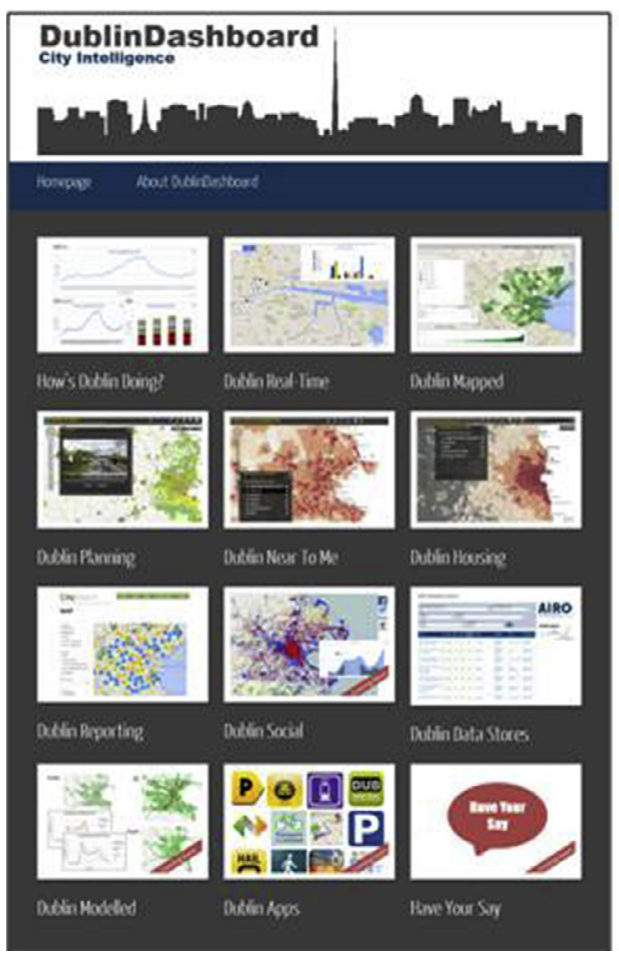

Mar 2014 - June 2014

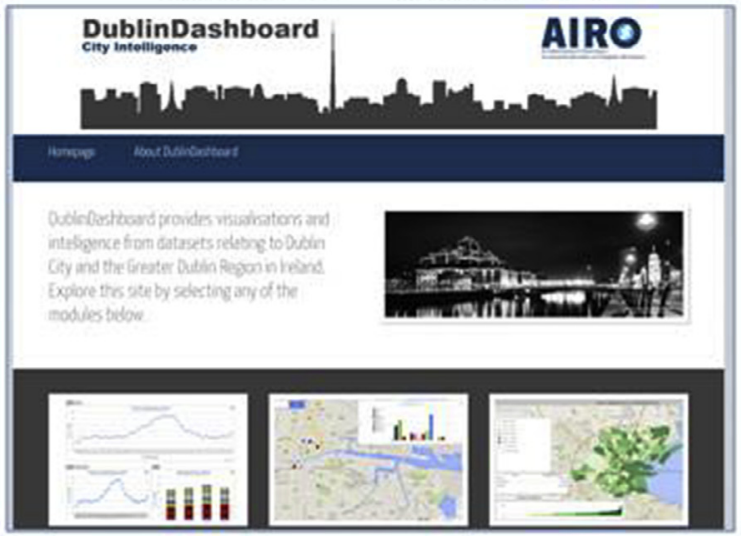

Feb 2015 -

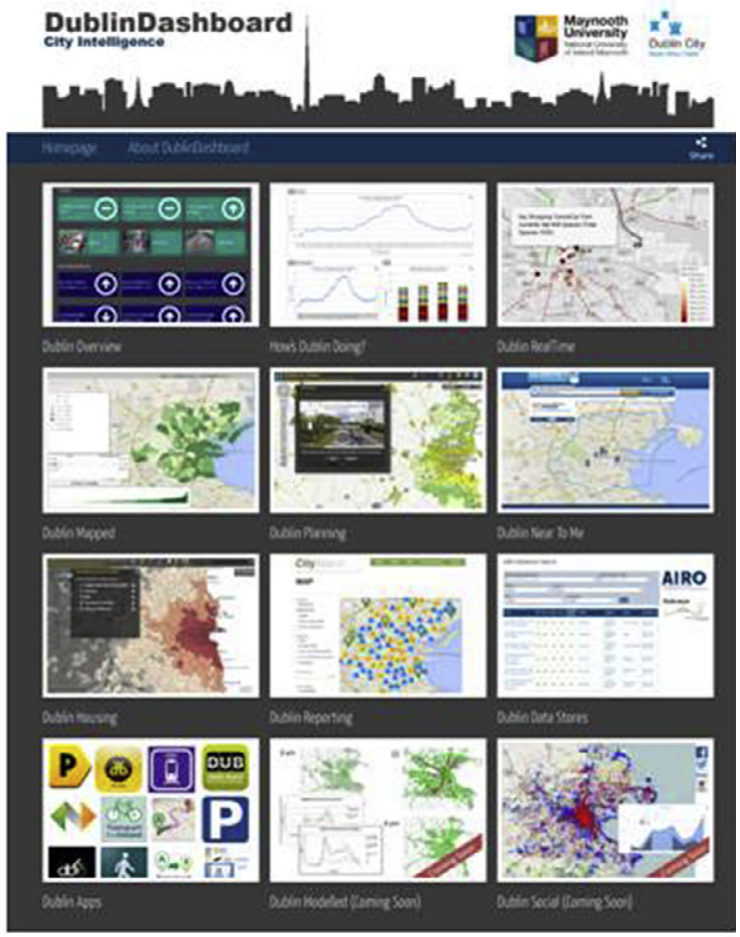

Fig. 1. Evolution of the Dublin Dashboard.

trary to normal practice we actively sought parameters and boundaries, in part because we did not want to build out the full system to then encounter problems later due to lack of early guidance. There was also a discussion at this meeting about including targets against indicators to indicate performance, but in the absence of already established set targets and the political nature of us imposing targets they were not pursued. Such targets are common on other city indicator systems, for example, Citistat and its derivatives. If such targets had been available then it is possible that a conflict point could have arisen between the developer team and DCC as the site would have partially shifted from providing context for decision making to supporting performance metric-driven governance and thus altering the underlying ethos and use of the site (see Kitchin et al., 2015).

In the weeks that followed there were several internal and external meetings to continue to iteratively plan and build the dashboard site. This included on-going decision making with respect to data set inclusion, reworking of the site's organisation, playing with the look and feel of the interface, email and phone exchanges with data holders, liaising with DCC offices to try and source data sets, or hunting through websites to discover data or interesting existing data visualisation projects for the city. These tasks were largely routine rather than disruptive and expanded the socio-technical assemblage constituting the dashboard. Sourcing data, however, continued to hamper development. Although now officially badged as a DCC initiative, the authority is a large organisation consisting of many different departments that effectively work as silos, and it was often quite difficult to locate data or find the right contact person. In general, once identified individuals and departments were open to providing data but lacked resources to make data available regularly or to automate the process by creating an API (Application Programming Interface). Only in a couple of cases were departments reluctant to make data available for other reasons (e.g., data protection, data security, cau- 
tion about exposing data to scrutiny). To try and overcome this issue we created a priority list for unlocking real-time data and liaised with the DCC Dublinked manager, who in turn liaised with other DCC staff.

By the end of July we were confident that we were nearing the point at which we could launch a comprehensive, although not fully functioning, dashboard, with eight out of the 12 modules operational, containing thousands of interactive graphs and maps. Our preference was to seek an early launch to demonstrate the dashboard in order to try and leverage additional data sets and working relationships with other data providers. We also knew that two of the remaining modules (social media analysis and modelling) were large tasks that required additional funding and would not be operational for some time. In mid-August we held an internal meeting, inviting colleagues not associated with the project to provide feedback on the look and feel and operation of the dashboard. A fairly extensive conversation unfolded as different elements of the site were queried and different solutions discussed, and the observations were used to tweak the design accordingly. Again, these alterations were minor rather than disruptive. After discussions with DCC the launch date was set for 19th September 2014 to be held in the council offices and the site went live on that date. Subsequently, the site continues to be worked on (it presently includes/links to 56 modules) and has recently received an additional four years of research funding.

\section{Unpacking the Dublin Dashboard}

This account of the initiation and building of the Dublin Dashboard makes a number of things clear about the nature of dashboards, their development and operation.

First, the dashboard is not simply a technical assemblage of networked infrastructure, hardware, operating systems, assorted software, data and an interface achieved through neutral, objective processes of scientific conception, engineering and coding. Rather, the dashboard is a complex socio-technical assemblage of actors (e.g., university researchers, DCC, other stakeholders) and actants (e.g., data, software, servers, standards) that work materially and discursively within a set of social and economic constraints, existing technologies and systems, and power geometries to assemble, produce and maintain the website. This assemblage is diversely constituted and evolves over time, and leads to an endless set of relations to be negotiated that directly shape the socio-technical system developed. Indeed, the constitution of an assemblage with conflicting parties can lead to the failure of an initiative. Moreover, in building the dashboard we had to be mindful of technical choices and constraints (not least the form or absence of suitable datasets), evaluate different potential technical solutions, and assess the success of solutions implemented. Importantly these did not happen in technical isolation, but within social, political, legal and financial context. Choices, solutions and assessment were debated, radically altered, and refined, the negotiations refracted through knowledge, experience and desires, and structured by resourcing, laws, standards, protocols, and power dynamics (the team is hierarchical; DCC control access to resources such as data, etc.). As such, whilst the completed dashboard appears stable and coherent, it is the product of an amalgam of interested parties, negotiated processes, and technologies and technical fixes.

Second, the production, maintenance and on-going research and development of dashboards unfold contingently and relationally. Dashboards evolve through a series of individuations and transductions (Mackenzie, 2002; Simondon, 1992; Kitchin and Dodge, 2011). Transduction is a process of ontogenesis, the making anew of a domain (e.g., a dashboard) through reiterative and transformative actions (Mackenzie, 2002). Like a crystal starting as a 'tiny seed which grows and extends itself in all directions in its mother-water' (Simondon, 1992: 313), with each layer of molecules serving as the structuring basis for the layer that is being formed next, the Dublin Dashboard accreted from its seed idea within the mother-water of the university and DCC. The process of transduction unfolds as a set of individuations (small incremental steps, or singular radical transformations) that provide partial, always incomplete solutions to relational problems (Mackenzie, 2002), where the problems in this case consisted of deciding which indicators and variable to include in the graphs and maps, determining how best to source, manage, process and visualise data, organize, design and implement the interface, implement forms of analysis, purchase the domain name, configure the servers, and so on. Individuations can consist of speech acts, physical movement, mental occurrences, memories, psychological perceptions, physiological sensations, and so on, with the process of individuation resulting in a modulation in conditions (e.g., incremental changes in the design, scope, function, organisation of the dashboard). Most individuations are ordinary - routine, habitual, banal (e.g., data is collected, inspected, cleaned, transformed) - others are more exceptional (e.g., deciding to radically extend the scope of the dashboard to include many more modules). Such a process of individuation is illustrated in the following discussion concerning site design that took place when reviewing on-going development:

R1: We just need to have a little rethink of design. I'm still tempted, on this bit here [points at screen], to do the same as at the top. Get rid of that line either side you know.

R2: Yeah.

R1: I might line them up, say with those two. [redirects pointing finger] Or maybe get rid of them.

R2: Start it here on the black.

R1: Yeah, tidy it up. But maybe we could do this and then at least there's a logic as to how they're laid out.

R2: mmhmm.

R1: Would you have to keep going up a level though to get back down again? How's it work at the minute if you go into the economy section?

R2: If you went to economy? Yeah, you can just go back to here if you went to, click here, you're back to the main page.

R1: You have to keep going back up?

R2: Yeah.

R1: There's no way of navigating on the lower level is there?

R2: I could put it in maybe. I could put them all across the top.

(Internal meeting 12 June 2014)

This process of individuation resulted in a design change in the Dashboard and the inclusion of a new interactive menu for navigating between indicator themes which is highlighted in Fig. 2. There are parallels here with the agile approach commonly seen in software development. Agile methods aim to produce quality software through an iterative process and when combined with user experience (UX) design approaches produce products where empathy with the end user is established and user experience is prioritised (Ferreira et al., 2011). Certainly, making a dashboard that was accessible and easy to use was a priority and a principle which, along with considering what types of information would be useful to users, guided the dashboard's development. An example of a more fundamental transduction was the decision to alter the scope of the dashboard to include as much data about the city as possible and to include links to tools not developed by the team, in turn adding to the underlying principles and the potential questions the site could help answer.

Understood in this way, the dashboard is ontogenetic in nature, constantly in a state of becoming; emerging citationally through a 


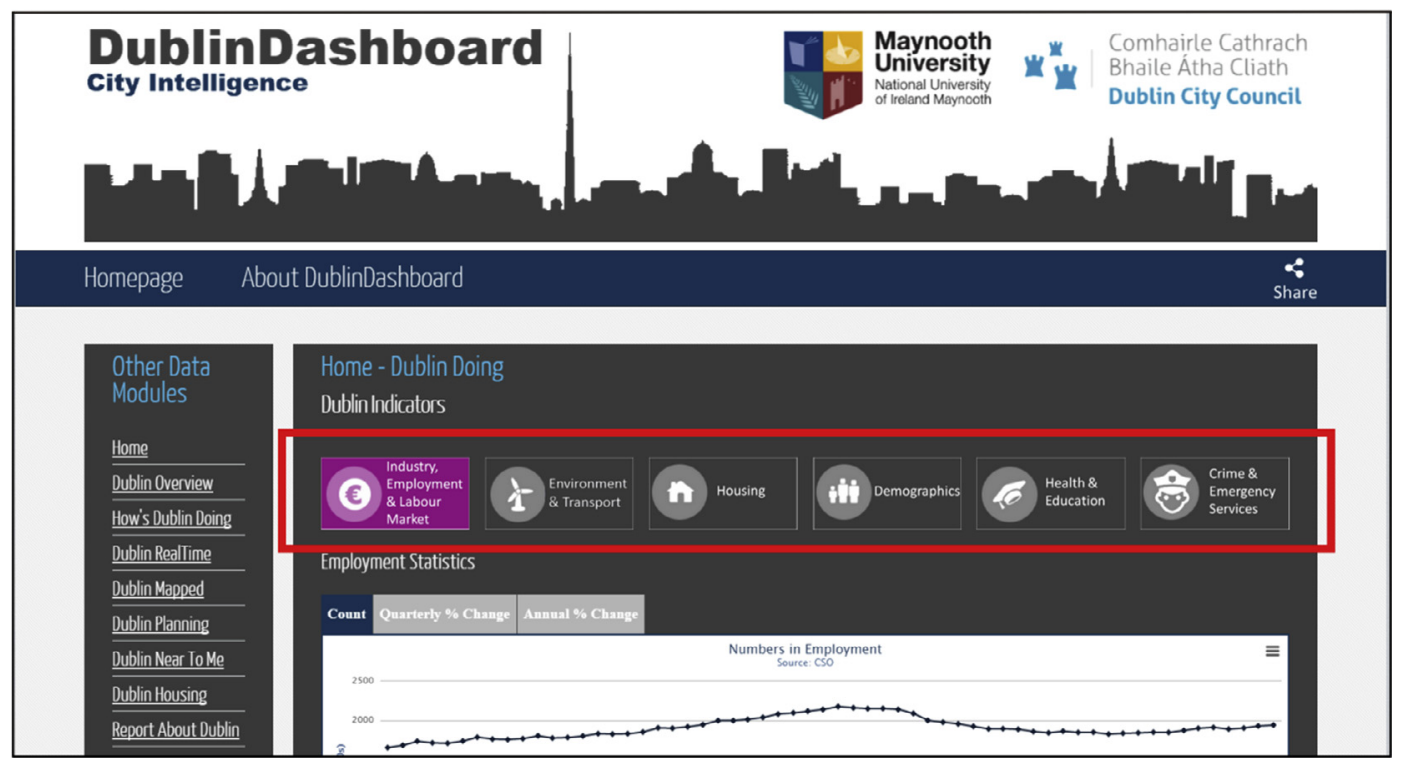

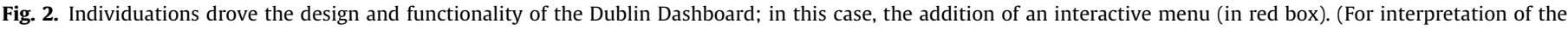
references to colour in this figure legend, the reader is referred to the web version of this article.)

series of provisional answers to relational questions. As noted above, these provisional answers are contingent on the wider context in which the dashboard is emerging, and are negotiated, contested, implemented, rescinded, re-instated, and re-visioned. Moreover solutions are enacted through the performativity of actors whom have varying subjectivities, personalities, knowledges and agendas, and are working together within specific social and institutional relations and settings, and are shaped by the capacities of other actants (e.g., the functionality and malleability of software; the data stock within repositories). And as new ideas and knowledges emerge, technologies are invented, organisations change their personnel, structures and policies, business models are created, political economies alter, regulations and laws introduced and repealed, skillsets develop, the dashboard potentially evolves and mutates accordingly. This continual process of becoming is in itself challenge, as the developer who built the dashboard lamented whilst coding to improve the colour scale gradient on the travel maps, "These little things take so much time and no-one sees it or understands." (11 September 2014). What this contingency and relationality means is that there is no right way to conceive and implement dashboards and no two dashboards will be identical in deployment (even if they are supposedly standardized offthe-shelf products).

Third, the praxis and politics of creating a dashboard has wider recursive effects. Just as building the dashboard was shaped by the wider institutional landscape, producing the system inflected that landscape, sometimes in profound ways. The discussions concerning the dashboard produced reflexivity within DCC about its data production and management and its wider smart cities strategy:

R1: There are two main issues for the organisation: How do we get the data and get it in the dashboard? How do we get the organisation to format its data into live feeds so we can pull it in directly? ... It's about data but it's also about the way that data is released. If it's in a JSON [JavaScript Object Notation] file it's automatic. If it's in a PDF [Portable Document Format] you have to cut and paste it. We need a live feed to link to.

DCC1: As an organisation we should set an example to put everything in JSON files which I think Dublinked is doing. But then we need to make sure our other organisations do the same thing.

DCC2: Putting structure to the data. Not just a dump of data. DCC1: We need to make this visible on our own website but also it needs to be visible on key partner websites. (DCC meeting 22 August 2014)

In this sense, the dashboard did not just cast light on how Dublin as a city was constituted and performing, but also cast light on DCC's management structure, the siloing of operations and data production across the organisation, as well as identifying shortcomings and gaps, and the fragmented and somewhat ad hoc approach to smart city development. This was already apparent to the organisation, hence the appointment of a smart city coordinator and the Dublinked manager prior to the project commencing, but the dashboard discussions provided critical dialogue and inflected reflection and change management. Moreover, the dashboard did lead to new data being opened and made available for use.

At the same time, our engagement with DCC and other state agencies altered our thinking with respect to the parameters, design and approach being taken and our perception of the issues and tasks at hand. It also inflected our wider thinking on smart city technologies and most specifically their messy and contested visioning and deployment by and within local authorities. Whilst the narrative spun by companies, and often also city management, suggests that the transition to a smart city is a smooth path of rollout and integration, the reality is a set of iterative processes of debate concerning needs, desires, specifications, technologies and costs framed by laws, governmentalities, budget, political ideologies and so on, and messy processes of implementation that are often resisted by units and staff who are used to existing systems and procedures and have limited resources to help effect change management. In entities as large and diverse as a city authority there are multiple overlapping visions and forces that continually jostle with one another, sometimes aligning, other times competing, whilst the institution as a whole tries to present a coherent set of policies and strategies for delivery. The localised production of a smart city then unfolds within this emergent context, its path 
dependency never assured, as our experience of building the dashboard attests.

Fourth, the data, configuration, tools, and modes of presentation of a dashboard produce a particularised set of spatial knowledges about the city. Whilst the dashboard might seek to show the city as it actually is, it is inevitably partial and limited. Dashboards only visualise a sample of the data that exists with respect to the city (even if it included all the data held by public agencies it would still exclude that held by private institutions and companies and citizens). The data included is generated in particular ways, with a selected field of view, a certain sampling frame, and biases and errors, shaped by the methods, technologies, calibration and data ontologies employed in producing and processing them (Kitchin, 2014b). Moreover, there are lots of data that do not exist, or exist with unsuitable spatial and temporal resolutions, as we discovered when conducting our data audit. Further, how the data can be presented is mutable, with dozens of potential modes of display that can be coloured and scaled in varying ways, each of which reveals and conceals different trends and patterns within the data. As Openshaw (1984) reveals, this can lead to all kinds of ecological fallacies, for example the modifiable areal unit problem wherein data displayed at different territorial scales reveal markedly different patterns and thus lead to varying conclusions. In other cases, data might have to be aggregated or transformed to comply with data protection laws. As such, dashboards provide oligoptic views of the world: views from certain vantage points, using particular tools, rather than an all-seeing view (Haraway, 1991; Amin and Thrift, 2002). Dashboards undoubtedly strive to be more exhaustive and provide dynamic, fine-grained insight but, nonetheless, their promise can never be fully fulfilled.

Moreover, even when seemingly fixed and static as a published website, the dashboard continues to be ontogenetic in nature. As Kitchin and Dodge (2007: 331) argue in relation to maps (of which there are hundreds in the Dublin dashboard), the data and visualizations within the dashboard are never static but are 'always in the process of being (re)made, brought into being through practices (embodied, social, technical).' As such, when one interacts with a dashboard its technicity (power to make things happen; Mackenzie, 2002) is evoked in context and in conjunction with the user to generate a particular spatiality, an instance of code/ space (Dodge and Kitchin, 2005). The spatiality and spatial knowledge presented enables the user to seek and deploy an incomplete answer to relational question (e.g., how is the city performing? what is happening in the city right now? what is the nearest facility to me and when is it open? what is the pattern of social inequality across the city? how can I report an issue to the city authorities? etc.)

\section{Conclusion}

Urban data are presently proliferating, as are ways to make sense and act on those data. Urban dashboards are one way to collate, process, visualise, analyze and share urban data, and are becoming more common as various cities invest in their development. The power of these dashboards is their assumed realist epistemology and instrumental rationality, and their supposed ability to translate the messiness and complexities of cities into rational, detailed, systematic, ordered forms of knowledge; to enable us to know the city as it actually is. In this paper, we have provided a critique of such a view by critically unpacking the building of the Dublin Dashboard drawing on participant observation, ethnography, and an archive of correspondence. Our analysis has challenged traditional scientific approaches to developing dashboards (and other smart city technologies) that largely treat them as neutral, commonsensical technical exercises and their underlying data as objective and value-free. Instead, we have highlighted the emergent politics and praxes of urban data and dashboard design; how the dashboard is a complex socio-technical assemblage that unfolds contextually, contingently and relationally, and produces diverse spatial knowledges about the city.

We have been careful, however, to avoid suggesting that because of the politics and praxes we have identified that dashboards have little utility. Rather, we believe, urban dashboards have much to offer city managers who need detailed information about the city to aid service delivery in a time of reduced budgets, companies who want to understand local markets and develop products based on open data, and citizens interested in finding out what is happening in a city. At the same time, it has to be recognized that dashboards provide partial views of a city that are inflected with the design choices and actions of their designers and commissioners, which emerge within contexts and structures. Following Kitchin et al. (2015), we thus contend that the creators and owners of dashboards need to explicitly recognize in their accounts of dashboard development that they constitute sociotechnical assemblages and that their underlying data and visualizations produce a particular understanding of the city, and likewise the policy produced and governance enacted on the basis of insights gained from the dashboard are the outcome of a specific epistemology.

As far as we are aware, this is the first in-depth empirical study of the development of an urban dashboard that treats them as socio-technical assemblages and adopts the perspective of critical data studies. It is our view that there is a pressing need for further such studies to widen the empirical base and enable comparison between dashboard initiatives and provide more evidence from which to conceptually unpack their creation. This future research would no doubt benefit from the use of other methodologies, such as in-depth interviews with all actors, tracing the interconnections and interdependencies of the various actants, and deconstructing the attendant code that determines how the dashboard looks and functions. Further, there is a need for research on the everyday uses of dashboards and how they are used by different constituencies (e.g., city managers, policy makers, citizens) for different purposes and within different spaces (e.g., within control rooms, within public spaces using displays, whilst travelling across a city), using different platforms (e.g., websites and mobile devices). And finally, there is a need to further develop our conceptual understanding of urban data and dashboards. We have provided one critical lens through which to make sense of urban dashboards, but we are aware that other approaches might provide additional useful insights.

\section{Acknowledgements}

The research for this paper was provided by a European Research Council Advanced Investigator Award, 'The Programmable City' (ERC-2012-AdG-323636). We are grateful to the members of AIRO, Dublin City Council and Dublinked who provided valuable support in building the Dublin Dashboard, and to Loretta Lees and Wendy Shaw and the two anonymous referees for feedback on an earlier version of this paper.

\section{References}

Amin, A., Thrift, N., 2002. Cities: Reimagining the Urban. Polity, London.

Behn, R.D., 2014. The PerformanceStat Potential: A Leadership Strategy for Producing. Brookings Institution Press/Ash Center, New York.

Block, T., Van Assche, J., Goeminne, G., 2013. Unravelling urban sustainability: How the Flemish City Monitor acknowledges complexities. Ecol. Inform. 17, 104110.

Brath, R., Peters, M., 2004. Dashboard design: Why design is important. DM Direct, October 2004. 
Craglia, M., Leontidou, L., Nuvolati, G., Schweikart, J., 2004. Towards the development of quality of life indicators in the 'digital' city. Environment and Planning B 31 (1), 51-64.

Dalton, C., Thatcher, J., 2014. What does a critical data studies look like, and why do we care? Seven points for a critical approach to 'big data'. Space and Society Open Site. <http://societyandspace.com/material/commentaries/craig-daltonand-jim-thatcher-what-does-a-critical-data-studies-look-like-and-why-dowe-care-seven-points-for-a-critical-approach-to-big-data/> (last accessed 17 July 2014).

Dodge, M., Kitchin, R., 2005. Code and the transduction of space. Ann. Assoc. Am. Geogr. 95 (1), 162-180.

Drucker, J., 2013. Performative materiality and theoretical approaches to interface. Dig. Humanities Quart. 7 (1) http://www.digitalhumanities.org/dhq/vol/7/1 000143/000143.html (last accessed 5 June 2014).

Dublin City Council, 2012. Sustainability Report 2012: Part B Sustainability Indicators. <http://dublincity.ie/sites/default/files/content/ WaterWasteEnvironment/Sustainability/Documents/SIR2012.pdf $>$ (last accessed 17 April 2015).

Dubriwny, D., Rivards, K., 2004. Are you drowning in bi reports? Using analytical dashboards to cut through the clutter. DM Rev. http:// wwwadvizorsolutions.com/press/Cut\%20Through\%20The\%20Clutter.pdf (last accessed 4 June 2014).

Dutton, W.H., Blumler, J.G., Kraemer, K.L., 1987. Wired Cities: Shaping Future Communication. Macmillan, New York.

Edwards, D., Thomas, J.C., 2005. Developing a municipal performance-measurement system: reflections on the Atlanta dashboard. Public Admin. Rev. 65 (3), 369 376.

Ferreira, J., Sharp, H., Robinson, H., 2011. User experience design and agile development: managing cooperation through articulation work. Softw. Pract. Exp. 41, 963-974.

Few, S., 2006. Information Dashboard Design: The Effective Visual Communication of Data. O'Reilly, Sebastopol.

Franceschini, F., Galetto, M., Maisano, D., 2007. Management by Measurement: Designing Key Indicators and Performance Measurement Systems. Springer, Berlin.

Galloway, A.R., 2012. The Interface Effect. Polity Press, Cambridge.

Graham, S., Marvin, S., 1999. Planning cybercities: integrating telecommunications into urban planning. Town Plan. Rev. 70 (1), 89-114.

Graham, S., Marvin, S., 2001. Splintering Urbanism. Routledge, London.

Greenfield, A., 2006. Everyware: The Dawning Age of Ubiquitous Computing. New Riders, Boston.

Gullino, S., 2009. Urban regeneration and democratization of information access: CitiStat experience in Baltimore. J. Environ. Manage. 90, 2012-2019.

Haraway, D., 1991. Simians, Cyborgs and Women: The Reinvention of Nature. Routledge, New York.

Holden, M., 2006. Urban indicators and the integrative ideals of cities. Cities 23 (3) $170-183$.

Innes, J., Booher, D.E., 2000. Indicators for sustainable communities: a strategy building on complexity theory and distributed intelligence. Plan. Theory Pract. 1 (2), 173-186.
Ishida, T., Isbister, K., 2000. Digital Cities: Technologies, Experiences, and Future Perspectives. Springer. LNCS, p. 1765.

Keim, D., Kohlhammer, J., Ellis, G., Mansmann, F., 2010. Mastering the Information Age - Solving Problems with Visual Analytics. Eurographics Association http:// www.vismaster.eu/book/ (last accessed 16th August 2013).

Kitchin, R., 2014a. The real-time city? Big data and smart urbanism. GeoJournal 79 (1), 1-14.

Kitchin, R., 2014b. The Data Revolution: Big Data, Open Data, Data Infrastructures and Their Consequences. Sage, London.

Kitchin, R., Dodge, M., 2007. Rethinking maps. Prog. Hum. Geogr. 31 (3), 331-344.

Kitchin, R., Dodge, M., 2011. Code/Space: Software and Everyday Life. MIT Press, Cambridge, MA.

Kitchin, R., Lauriault, T., 2014. Towards critical Data Studies: Charting and Unpacking Data Assemblages and their Work. The Programmable City Working Paper 2, SSRN.

Kitchin, R., Lauriault, T., McArdle, G., 2015. Knowing and governing cities through urban indicators, city benchmarking and real-time dashboards. Reg. Stud. Reg. Sci. 2, 1-28.

Komninos, N., 2002. Intelligent Cities: Innovation, Knowledge Systems and Digital Spaces. Routledge, London.

Luque-Ayala, A., Marvin, S., 2016. The maintenance of urban circulation: an operational logic of infrastructural control. Environ. Plann. D Soc. Space 34 (2), 191-208.

Mackenzie, A., 2002. Transductions: Bodies and Machines at Speed. Continuum Press, London.

Mattern, S., 2014. Interfacing urban intelligence. Places: Des. Observer http://places. designobserver.com/feature/how-do-we-interface-with-smart-cities/38443 (last accessed 17 July 2014).

Mattern, S., 2015. Mission control: a history of the urban dashboard. Places J. https://placesjournalorg/article/mission-control-a-history-of-the-urbandashboard/ (last accessed 16 April 2015).

Mori, K., Christodoulou, A., 2012. Review of sustainability indices and indicators: Towards a new City Sustainability Index (CSI). Environ. Impact Assess. Rev. 32, 94-106.

Openshaw, S., 1984. The modifiable areal unit problem. Concepts and Techniques in Modern Geography, vol. 38. Geo Books, Norwich.

Sawicki, D.S., Flynn, P., 1996. Neighborhood indicators: a review of the literature and an assessment of conceptual and methodological issues. J. Am. Plan. Assoc. 62 (2), 165-183.

Shepard, M., 2011. Sentient City: Ubiquitous Computing, Architecture, and the Future of Urban Space. MIT Press, Cambridge, Mass.

Simondon, G., 1992. The genesis of the individual. In: Crary, J., Kwinter, S. (Eds.), Incorporations 6. Zone Books, New York, pp. 296-319.

Townsend, A., 2013. Smart Cities: Big Data, Civic Hackers, and the Quest for a New Utopia. W.W. Norton \& Co.

Wong, C., 2006. Indicators for Urban and Regional Planning: The Interplay of Policy and Methods. Routledge, London and New York. 